\title{
Modelling and Analysis of Dual-Stator Induction Motors
}

\author{
Hubert Razik* \\ Non-member \\ Abderrezak Rezzoug* \\ Non-member \\ Djafar Hadiouche ${ }^{* *}$ \\ Non-member
}

In this paper, the analysis and the modelling of a Dual-Stator Induction Motor (DSIM) are presented. In particular, the effects of the shift angle between its three-phase windings are studied. A complex steady state model is first established in order to analyse its harmonic behavior when it is supplied by a non-sinusoidal voltage source. Then, a new transformation matrix is proposed to develop a suitable dynamic model. In both cases, the study is made using an arbitrary shift angle. Simulation results of its PWM control are also presented and compared in order to confirm our theoretical observations.

Keywords: multi-machine multi-converter systems, multi-stator AC machines, dual-stator induction motors, voltage source inverter, PWM control, modelling

\section{Introduction}

High power AC machines have found a lot of applications. But when they are supplied by a voltage source converter, strong constraints appear on power electronic devices and limit their switching frequency. The concept of power segmentation has then emerged to allow the use of Voltage Source Inverter (VSI) with reduced size power electronic devices. There are different ways to achieve it. One of them is to use multi-level inverter fed AC machines. In this case, the voltage stress is shared between the different devices connected in series. This solution has been greatly developed and studied from the past. Another way is to use multi-phase machines or multi-star machines. For this kind of structure, each phase or each star is fed by its own VSI. The current per phase is then reduced without increasing the voltage per phase. Moreover, this solution improves the reliability ${ }^{(1)}$ since the loss of one or many phases does not prevent the motor from starting and running, but it implies a reduction of the torque and increases losses, of course. However, it is obvious that the performance of these machines in unbalanced operations becomes better when the total number of phases increases. One common example of such structure is the Dual-Stator Induction Motor (DSIM) fed by two three-phase VSI's. This is a rather good compromise between a sufficient power segmentation and a not too complicated system. In the usual configuration, two sets of three-phase windings are spatially shifted by an electrical angle of 30 degrees $^{(2)-(4)}$. The main specific advantage of this motor is the elimination of the sixth harmonic torque pulsation, usually encountered in inverter fed three-phase motors. Another asset is that all space harmonics below the eleventh are eliminated.

Nevertheless, this VSI fed DSIM is subject to large stator circulating harmonic currents ${ }^{(5)(6)}$. These currents are at the

\footnotetext{
* GREEN-UHP, CNRS UMR-7037, Université Henri Poincaré, BP 239 F-54506 Vandoeuvre-les-Nancy, Cedex, France

** GE Fanuc Automation Solutions Europe S.A. Zone Industrielle L-6468 Echternach
}

origin of extra losses and require larger semiconductor device ratings. In fact, for some particular orders of time harmonic, the air gap Magneto Motive Forces (MMF) produced by the two stars cancel each other. Thus, the corresponding stator harmonic currents only circulate between both stars, without any effect into the rotor. So, the motor impedance for these harmonics can be quite small, especially at low order. For current source inverters (CSI), the current harmonic spectrum is determined by the current waveform alone, and the above-mentioned inaccurate harmonic currents can be controlled with PWM. That is the reason why DSIM's have been commonly used with CSI's. On the contrary, with VSI's, the harmonic currents are determined not only by the harmonic voltages, but also by the corresponding motor impedance. So, they can reach high values. Consequently, these problems let us think that other configurations of double-star windings should perhaps be considered and investigated. The study is not easy because the effects of time harmonics are very important. Several models have been already developed, but few of them allow to study the DSIM with an arbitrary shift angle between its two sets of three-phase windings.

In this paper, the analysis and the modelling of a DualStator Induction Motor are presented. In particular, the effects of the shift angle between its two three-phase windings are studied. A complex steady state model is first established in order to analyse its harmonic behavior when it is supplied by a non-sinusoidal voltage source. Then, a new transformation matrix is proposed to develop a suitable dynamic model. In both cases, the study is made using an arbitrary shift angle. Simulation results of its PWM control are also presented and compared to confirm the theoretical observations.

\section{Complex Steady State Model}

The first aim of this paper is to study the steady state behavior of the DSIM, even if it is not a commonly used approach. Steady state models are easy to establish, because they do not necessitate the use of any transformation to study balanced operations. They also allow to make a harmonic 
analysis, which is fundamental in the study of multi-phase AC machines and multi-star AC machines ${ }^{(7)(8)}$. The windings of the motor are shown in Fig. 1. The stator is wound with two three-phase windings spatially shifted by a fixed but arbitrary electrical angle $\alpha^{(9)(10)}$. The rotor can be a shortcircuited three-phase winding one or a squirrel cage one. For simplicity, a wound rotor is considered here.

In order to derive the model, the following general assumptions are made:

- motor windings are equivalent sinusoidally field distributed;

- both stars have the same parameters;

- flux path is linear;

- magnetic saturation effects are negligible;

- magnetic hysteresis is negligible;

- the stator leakage inductance is supposed to be constant whatever the value of the shift angle.

The last assumption will be explained later. The voltage equation is:

$$
\left[\begin{array}{l}
\mathbf{V s} \\
\mathbf{V r}
\end{array}\right]=\left[\begin{array}{ll}
\mathbf{R s} & \mathbf{0}_{6 \times 3} \\
\mathbf{0}_{3 \times 6} & \mathbf{R r}
\end{array}\right]\left[\begin{array}{l}
\mathbf{I s} \\
\mathbf{I r}
\end{array}\right]+\frac{d}{d t}\left[\begin{array}{l}
\boldsymbol{\Psi} \mathbf{s} \\
\boldsymbol{\Psi} \mathbf{r}
\end{array}\right] \cdots(1)
$$

with:

$$
\left[\begin{array}{c}
\Psi \mathbf{s} \\
\mathbf{\Psi r}
\end{array}\right]=\left[\begin{array}{cc}
\mathbf{L s s} & \mathbf{M s r} \\
\mathbf{M s r}^{T} & \mathbf{L r}
\end{array}\right]\left[\begin{array}{c}
\mathbf{I s} \\
\mathbf{I r}
\end{array}\right]
$$

where the vector of stator variables are defined as:

$$
\mathbf{G}_{\mathbf{s}}=\left[g s a_{1} g s b_{1} g s c_{1} g s a_{2} g s b_{2} g s c_{2}\right]^{T} .
$$

and the vector of rotor variables is:

$$
\mathbf{G}_{\mathbf{r}}=[\operatorname{gragrb} g r c]^{T}
$$

The resistance matrices of Eq. 1 are given by:

$$
\begin{aligned}
& \mathbf{R s}=R s \mathbf{I}_{6 \times 6} \\
& \mathbf{R r}=\operatorname{Rr} \mathbf{I}_{3 \times 3} \\
& \mathbf{L r}=\operatorname{Lm}\left[\begin{array}{ccc}
1+k l r & \cos \left(\frac{2 \pi}{3}\right) & \cos \left(\frac{4 \pi}{3}\right) \\
\cos \left(\frac{4 \pi}{3}\right) & 1+k l r & \cos \left(\frac{2 \pi}{3}\right) \\
\cos \left(\frac{2 \pi}{3}\right) & \cos \left(\frac{4 \pi}{3}\right) & 1+k l r
\end{array}\right] \ldots \ldots
\end{aligned}
$$

with: $k l r=\frac{L l r}{L m r}$.

The detail of the submatrixes Lss and Msr are given in equations 8 and 9 .

The coefficient $k l s$ and $M s r$ are given by:

$$
\begin{aligned}
& k l s=\frac{L l s}{L m s} \\
& M s r=\frac{N r}{N s} L m s
\end{aligned}
$$

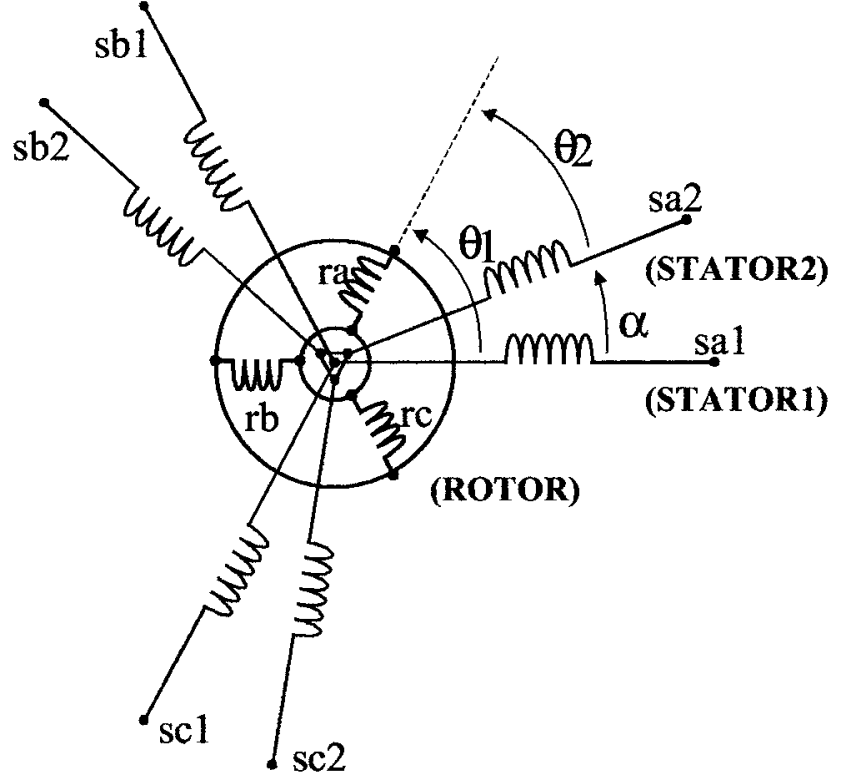

Fig. 1. Windings of the DSIM

$R s, L l s$ and $L m s$ are the stator resistance, leakage inductance and magnetizing inductance. $R r, L l r$ and $L m r$ are the rotor resistance, leakage inductance and magnetizing inductance. $N s$ and $N r$ are the number of turns of the stator and rotor windings.

Since the machine is supposed to be under linear conditions, the superposition theorem can be applied to any variables. In complex notation, all of them can be written as follows:

$$
\bar{g}=\sqrt{2} \sum_{h=1}^{\infty} \bar{G}_{h} e^{j \omega s t}
$$

where $h$ denotes the order of the time harmonics and $\omega s$ the synchronism velocity.

Since the two three-phase windings are wye-connected with isolated neutrals, there is no zero-sequence harmonic current. So, only harmonics of order $3 k \pm 1(k=0,1,2,3 \ldots)$ are considered. By this way, a complex model can be carried out. Stator and rotor harmonic currents can be calculated by solving the following system of equations 11 where $g_{h}$ is the harmonic slip. With a new definition of rotor variables, Eq. 11 becomes Eq. 12 .

From this system, an equivalent circuit (Fig. 2) can be depicted. It appears that harmonics can be classified in several groups, according to their order and to the value of the shift angle $\alpha$ between both stars. As an example, it is easily shown that for the usual configuration $\left(\alpha=30^{\circ}\right)$, the harmonic group of order $12 k \pm 1(k=0,1,2,3)$ and the harmonic group of

$$
\text { LsS }=\text { Lms }\left[\begin{array}{llllll}
1+k l s & \cos \left(\frac{2 \pi}{3}\right) & \cos \left(\frac{4 \pi}{3}\right) & \cos (\alpha) & \cos \left(\alpha+\frac{2 \pi}{3}\right) & \cos \left(\alpha+\frac{4 \pi}{3}\right) \\
\cos \left(\frac{4 \pi}{3}\right) & 1+k l s & \cos \left(\frac{2 \pi}{3}\right) & \cos \left(\alpha-\frac{2 \pi}{3}\right) & \cos (\alpha) & \cos \left(\alpha+\frac{2 \pi}{3}\right) \\
\cos \left(\frac{2 \pi}{3}\right) & \cos \left(\frac{4 \pi}{3}\right) & 1+k l s & \cos \left(\alpha-\frac{4 \pi}{3}\right) & \cos \left(\alpha-\frac{2 \pi}{3}\right) & \cos (\alpha) \\
\cos (\alpha) & \cos \left(\alpha-\frac{2 \pi}{3}\right) & \cos \left(\alpha-\frac{4 \pi}{3}\right) & 1+k l s & \cos \left(\frac{2 \pi}{3}\right) & \cos \left(\frac{4 \pi}{3}\right) \\
\cos \left(\alpha+\frac{2 \pi}{3}\right) & \cos (\alpha) & \cos \left(\alpha-\frac{2 \pi}{3}\right) & \cos \left(\frac{4 \pi}{3}\right) & 1+k l s & \cos \left(\frac{2 \pi}{3}\right) \\
\cos \left(\alpha+\frac{4 \pi}{3}\right) & \cos \left(\alpha+\frac{2 \pi}{3}\right) & \cos (\alpha) & \cos \left(\frac{2 \pi}{3}\right) & \cos \left(\frac{4 \pi}{3}\right) & 1+k l s
\end{array}\right.
$$$$
\mathbf{M s r}^{T}=M \boldsymbol{s r}\left[\begin{array}{llllll}
\cos \left(\theta_{1}\right) & \cos \left(\theta_{1}-\frac{2 \pi}{3}\right) & \cos \left(\theta_{1}-\frac{4 \pi}{3}\right) & \cos \left(\theta_{1}-\alpha\right) & \cos \left(\theta_{1}-\alpha-\frac{2 \pi}{3}\right) & \cos \left(\theta_{1}-\alpha-\frac{4 \pi}{3}\right) \\
\cos \left(\theta_{1}+\frac{2 \pi}{3}\right) & \cos \left(\theta_{1}\right) & \cos \left(\theta_{1}-\frac{2 \pi}{3}\right) & \cos \left(\theta_{1}-\alpha+\frac{2 \pi}{3}\right) & \cos \left(\theta_{1}-\alpha\right) & \cos \left(\theta_{1}-\alpha-\frac{2 \pi}{3}\right) \\
\cos \left(\theta_{1}+\frac{4 \pi}{3}\right) & \cos \left(\theta_{1}+\frac{2 \pi}{3}\right) & \cos \left(\theta_{1}\right) & \cos \left(\theta_{1}-\alpha+\frac{4 \pi}{3}\right) & \cos \left(\theta_{1}-\alpha+\frac{2 \pi}{3}\right) & \cos \left(\theta_{1}-\alpha\right)
\end{array}\right]
$$ 


$$
\begin{aligned}
& \begin{cases}\overline{V s h} & =\left[R s+j\left(L l s+\frac{3}{2} L m s \cdot\left(1+e^{-j 3 k \alpha}\right)\right) h \cdot \omega s\right] \overline{I s h}+j \frac{3}{2} M s r \cdot h \cdot \omega s \cdot \overline{I r h} \\
\overline{V s h} \cdot e^{-j 3 k \alpha} & =\left[R s+j\left(L l s+\frac{3}{2} L m s \cdot\left(1+e^{j 3 k \alpha}\right)\right) h \cdot \omega s\right] \overline{I s h} \cdot e^{-j 3 k \alpha}+j \frac{3}{2} M s r \cdot h \cdot \omega s \cdot \overline{I r h} \\
0 & =\left[\frac{R r}{g h}+j\left(L l r+\frac{3}{2} L m r\right) h \cdot \omega s\right] \overline{I r h}+j \frac{3}{2} M s r \cdot h \cdot \omega s\left(1+e^{-j 3 k \alpha}\right) \overline{I s h}\end{cases} \\
& \begin{cases}\overline{V s h} & =[R s+j L l s \cdot h \cdot \omega s] \overline{I s h}+j \frac{3}{2} L m s \cdot h \cdot \omega s\left[\overline{I s h}\left(1+e^{-j 3 k \alpha}\right)+\overline{I r h^{\prime}}\right] \\
\overline{V s h} \cdot e^{-j 3 k \alpha} & =[R s+j L l s . h \cdot \omega s] \overline{I s h} \cdot e^{-j 3 k \alpha}+j \frac{3}{2} L m s \cdot h \cdot \omega s\left[\overline{I s h}\left(1+e^{-j 3 k \alpha}\right)+\overline{I r h^{\prime}}\right] \\
0 & =\left[\frac{R r^{\prime}}{g h}+j L l r^{\prime} \cdot h \cdot \omega s\right] \overline{I r h^{\prime}}+j \frac{3}{2} L m s \cdot h \cdot \omega s\left[\overline{I s h}\left(1+e^{-j 3 k \alpha}\right)+\overline{I r h^{\prime}}\right]\end{cases}
\end{aligned}
$$

order $6(2 k-1) \pm 1(k=1,2,3,4)$ have different equivalent circuits. The first one participates to the electromechanical energy conversion whereas the second one does not.

This is due to the term $\left(1+e^{-j 3 k \alpha}\right)$ in the third equation of Eq. 12 , if it is equal to 0 , rotor harmonic currents are zero. In this case, stator harmonic currents are non-electromechanical energy conversion related and they only circulate between both stators, without any effect into the rotor. So it can be convenient to call the first group the type $\mathrm{C}$ harmonics ( $\mathrm{C}$ as Conversion), and the second group the type $\mathrm{NC}$ harmonics (NC as No Conversion). Of course, for each value of $\alpha$, there is a particular set of type $\mathrm{C}$ and type $\mathrm{NC}$ harmonics. In order to obtain the steady state equivalent circuits for type $\mathrm{C}$ and type NC harmonics, the following variables are introduced:

$$
\begin{aligned}
& \overline{G s h}_{C}=\frac{\overline{G s h} .\left(1+e^{-j k k \alpha}\right)}{2} \\
& \overline{G s h}_{N C}=\frac{\overline{G s h} .\left(1-e^{-j 3 k \alpha}\right)}{2}
\end{aligned}
$$

and

$$
\overline{G s h}=\overline{G s h}_{C}+\overline{G s h}_{N}
$$

It must be noticed that the voltages applied to both stars have been supposed to have the same amplitude and the same shape, that is to say: $\overline{v s h}_{1}=\overline{v s h}_{2}=\overline{v s h}$. In the general case, the variables introduced before are:

$$
\begin{aligned}
& \overline{G s h}_{C}=\frac{\overline{G s h_{1}}+\overline{G s h}_{2} \cdot e^{-j 3 k \alpha}}{\overline{G s h_{N C}}}=\frac{2 \overline{G s h}_{1}-\overline{G s h}_{2} \cdot e^{-j 3 k \alpha}}{2} \\
& \overline{G s}
\end{aligned}
$$

and

$$
\begin{array}{ll}
\overline{G s h}_{1} & =\overline{G s h}_{C}+\overline{G s h}_{N C} \\
\overline{G s h}_{2} . e^{-j 3 k \alpha} & =\overline{G s h}_{C}-\overline{G s h}_{N C}
\end{array}
$$

Hence, the circuit of Fig. 2 is decomposed into two independent equivalent circuits shown in Fig. 3 and Fig. 4. For the type $\mathrm{C}$ harmonics, a usual per phase equivalent circuit is obtained. However, for the type NC harmonics, the resulting equivalent circuit is composed only by the stator resistance and leakage inductance, which is a quite small impedance for the low order harmonics.

When the DSIM is fed by CSI's ${ }^{(11)-(13)}$, it is obvious that this impedance should be as small as possible to minimise the inaccurate type NC harmonic voltages, and the commutating reactance which determines the peak commutating voltage. This peak is a limiting factor in pushing up the horsepower rating of CSI drives.

On the contrary, when the DSIM is fed by VSI's, the above mentioned impedance should be maximum in order to limit the currents and their own harmonics of type NC. These ones implies the appearance of high values currents and consequently, produce important additional losses in the motor as

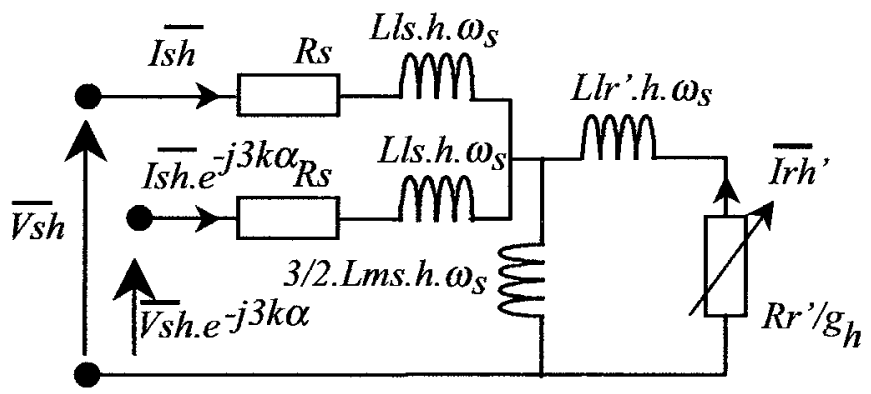

Fig. 2. Steady state equivalent circuit

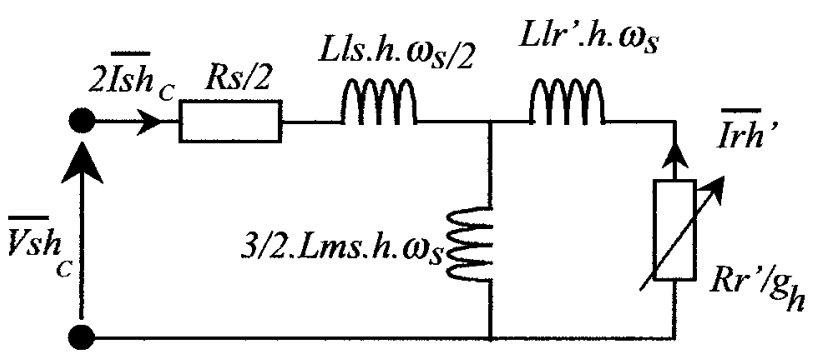

Fig. 3. Steady state equivalent circuit for type C harmonics

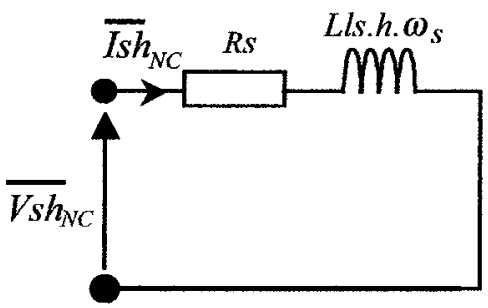

Fig. 4. Steady state equivalent circuit for type NC harmonics

in the VSI's. That is why larger semiconductor device ratings are required. As a consequence, type NC harmonics must always be avoided as much as possible.

\section{Analysis}

A complete analysis of Eq. 12 allows to determine, for some values of the shift angle $\alpha$, which harmonics are type $\mathrm{C}$ and which ones are type NC. Table 1 presents the results of $\left(1+e^{-j 3 k \alpha}\right)$, according to $\alpha$ and to the order of harmonics $h$. So, it indicates the existence or non-existence of rotor harmonic currents when the stator windings are supplied by balanced non-sinusoidal voltages.

Only zero sequence harmonics (of order $h o=3 k$ ) have not been reported. Even order harmonics, which are generally neglected because of the supposed symmetrical waveforms of the voltages applied to the motor, are considered here.

In Table 1, the stator harmonic currents contributing to the 
Table 1. Value of $\left(1+e^{-j 3 k}\right)$ according to the shift angle and to the order of harmonics $h$

\begin{tabular}{|l||l|l|l|l|l|l|l|l|l|l|l|l|l|l|l|l|}
\hline \hline$\alpha \backslash h$ & 1 & 2 & 4 & 5 & 7 & 8 & 10 & 11 & 13 & 14 & 16 & 17 & 19 & 20 & 22 & 23 \\
\hline \hline $0^{\circ}$ & 2 & 2 & 2 & 2 & 2 & 2 & 2 & 2 & 2 & 2 & 2 & 2 & 2 & 2 & 2 & 2 \\
\hline $30^{\circ}$ & 2 & $1-j$ & $1-j$ & 0 & 0 & $1+j$ & $1+j$ & 2 & 2 & $1-j$ & $1-j$ & 0 & 0 & $1+j$ & $1+j$ & 2 \\
\hline $60^{\circ}$ & 2 & 0 & 0 & 2 & 2 & 0 & 0 & 2 & 2 & 0 & 0 & 2 & 2 & 0 & 0 & 2 \\
\hline $90^{\circ}$ & 2 & $1+j$ & $1+j$ & 0 & 0 & $1-j$ & $1-j$ & 2 & 2 & $1+j$ & $1+j$ & 0 & 0 & $1-j$ & $1-j$ & 2 \\
\hline $120^{\circ}$ & 2 & 2 & 2 & 2 & 2 & 2 & 2 & 2 & 2 & 2 & 2 & 2 & 2 & 2 & 2 & 2 \\
\hline \hline
\end{tabular}
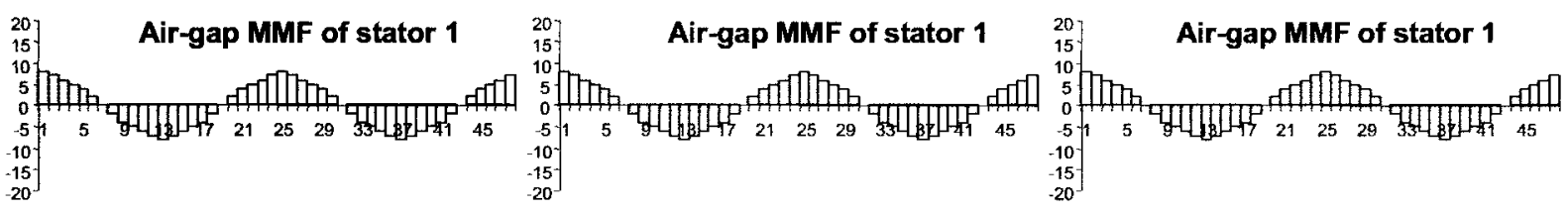

Air-gap MMF of Stator $2\left(30^{\circ}\right)$

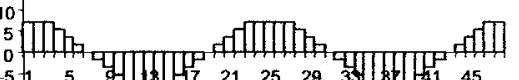
$\begin{array}{ccccc}57 & 5 \\ 10.7 & 5 \\ 15 . & \end{array}$

15
-20
-1

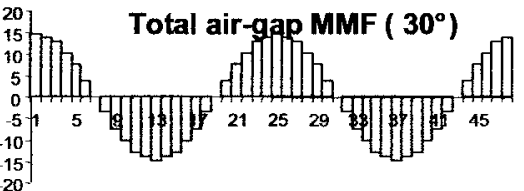

a: $\alpha=30^{\circ}$, type $\mathrm{C}$,

$h=6(2 k) \pm 1(k=0,1,2,3 \ldots)$

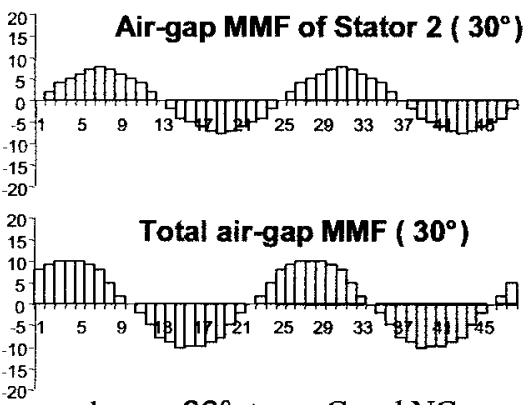

b: $\alpha=30^{\circ}$, types $\mathrm{C}$ and $\mathrm{NC}$, $h=3(2 k-1) \pm 1(k=1,2,3,4 \ldots)$
Air-gap MMF of Stator $2\left(30^{\circ}\right)$

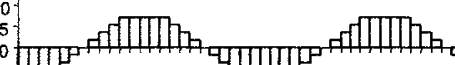

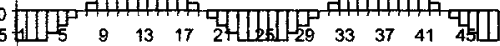
-10
-15
-20

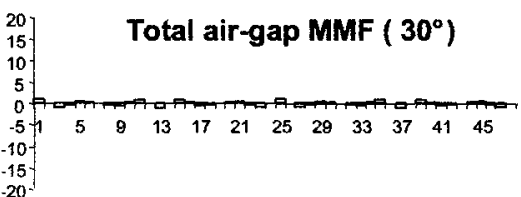

c: $\alpha=30^{\circ}$, type $\mathrm{NC}$ $h=6(2 k-1) \pm l(k=1,2,3,4 \ldots)$

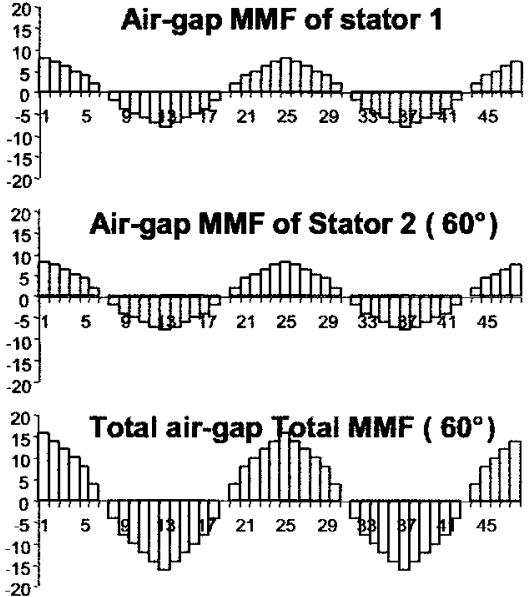

$\mathrm{d}: \alpha=60^{\circ}$, type C $h=6 k \pm 1(k=0,1,2,3 \ldots)$

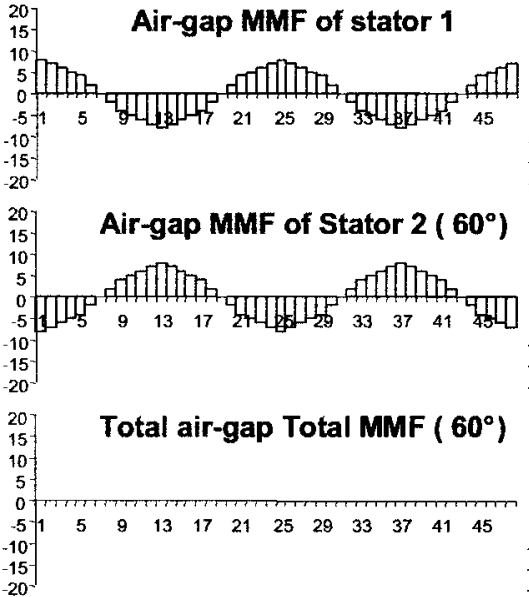

e: $\alpha=60^{\circ}$, type NC

$h=3(2 k-1) \pm 1(k=1,2,3,4 \ldots)$

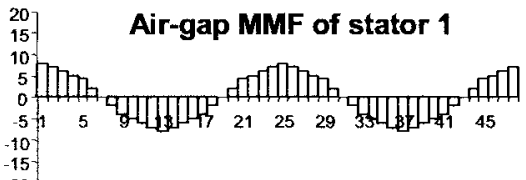

Air-gap MMF of Stator $2\left(0^{\circ}\right)$ 年 $-15$.

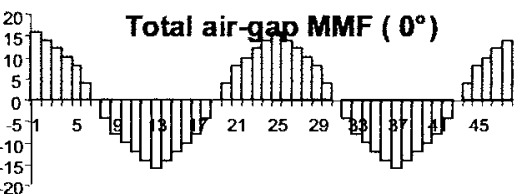

f: $\alpha=0^{\circ}$, type C

$h=3 k \pm 1(k=0,1,2,3 \ldots)$

Fig. 5. Stator air gap MMF's produced by harmonic currents function of the stator slot rank (48 slots, 4 poles dual stator winding)

energy conversion (type C) have the value 2 in the cells and it means that:

$$
\begin{aligned}
& \overline{V s h}_{C}=\overline{V s h}, \overline{I s h}_{C}=\overline{I s h} . \\
& \overline{V s h}_{N C}=0, \overline{I s h}_{N C}=0 \cdots
\end{aligned}
$$

The value 0 means, on the contrary, that the stator harmonic currents are type NC only:

$$
\begin{aligned}
& \overline{V s h}_{C}=0, \overline{I s h}_{C}=0 \ldots \ldots \ldots \\
& \overline{V s h}_{N C}=\overline{V s h}, \overline{I s h}_{N C}=\overline{I s h} .
\end{aligned}
$$

In this case, no rotor harmonic current can be produced and the stator harmonic currents circulate only between the two stator windings, through the small impedance shown in
Fig. 4.

When the value is $1 \pm j$, it means that the stator harmonic currents are both type $\mathrm{C}$ and type NC. In fact, in this case both type $\mathrm{C}$ and type $\mathrm{NC}$ equivalent circuits are excited:

$$
\begin{aligned}
& \overline{V s h}_{C}=\frac{\sqrt{2}}{2} \overline{V s h} e^{ \pm J \frac{\pi}{4}}, \overline{I s h}_{C}=\frac{\sqrt{2}}{2} \overline{I s h} e^{ \pm j \frac{\pi}{4}} \ldots . . \\
& \overline{V s h}_{N C}=\frac{\sqrt{2}}{2} \overline{V s h} e^{\mp J \frac{\pi}{4}}, \overline{I s h}_{N C}=\frac{\sqrt{2}}{2} \overline{I s h} e^{\mp J \frac{\pi}{4}} \ldots
\end{aligned}
$$

Another way to explain the difference between the harmonics is to look at the MMF's produced. Figure 5 shows the stator air-gap MMF's produced by the harmonic currents with a full pitch 4 poles dual-stator winding, each one having 2 conductors per coil with a current of $1 \mathrm{~A}$. 
For the type $\mathrm{C}$ harmonics (2 in Table 1), the rotating MMF's produced by the two stators are in phase. Hence the total MMF is a rotating one. It is the case for $\alpha=30^{\circ}$ when $h=6(2 k) \pm 1(k=0,1,2,3 \ldots), \alpha=60^{\circ}$ when $h=6 k \pm 1$ $(k=0,1,2,3 \ldots)$ and $\alpha=0^{\circ}$ when $h=3 k \pm 1(k=0,1,2$, 3...) (see Fig. 5 a, d and f).

For the type NC harmonics (0 in Table 1$)$, the rotating MMF's produced by the two stators are out of phase. So, they cancel each other and the total MMF is zero. There is no rotating MMF for these harmonics and consequently no rotor current is produced. It is the case for $\alpha=30^{\circ}$ when $h=6(2 k-1) \pm 1(k=1,2,3,4 \ldots)$ and $\alpha=60^{\circ}$ when $h=3(2 k-1) \pm 1(k=1,2,3,4 \ldots)$ (see Fig. $5 \mathrm{c}$ and e). That is why for $\alpha=30^{\circ}$, the sixth harmonic torque pulsation, which is produced by the 5th and 7th harmonics in inverter fed three-phase motors ${ }^{(14)}$, is completely eliminated.

For those remaining harmonics, which imply a $1 \pm j$ entry in Table 1, the rotating MMF's produced by the two stators are in quadrature. Accordingly, each of them has one part which contributes to the total rotating MMF, and one part cancelled. It is the case for $\alpha=30^{\circ}$ when $h=3(2 k-1) \pm 1(k=1,2,3$, 4...) (see Fig. 5 b).

It is noticed that all the even order harmonics are type NC for the case $\alpha=60^{\circ}$. So, although the voltage waveforms generated by the inverter contain negligible even order harmonics, careful attention must be paid because they contribute to create the extra current called $\overline{I s h}_{N C}$. In fact, the switching frequency must be taken into account, and not be chosen in such a way that the switching harmonic is an even order one.

For $\alpha=0^{\circ}$, type NC harmonics does not exist. However, in unbalanced operations $\overline{V s h}_{1} \neq \overline{V s h}_{2}$ and $\overline{V s h}_{N C}$ is always different from zero.

These observations will be verified by simulation, using an adequate dynamic model. As in three-phase systems, the use of a transformation matrix leads to express the variables in an orthogonal base.

\section{Dynamic Model}

4.1 Transformation Matrix If we write the fundamental component of the air-gap MMF produced by the two stars, we obtain the expression hereafter, where $\theta s$ denotes the position of a point in the air-gap:

$$
\begin{aligned}
M M F(\theta s) & =K \cdot\left[i s a_{1} \cdot \cos \theta s+i s a_{2} \cdot \cos (\theta s-\alpha)\right. \\
& +i s b_{1} \cdot \cos \left(\theta s-\frac{2 \pi}{3}\right)+i s b_{2} \cdot \cos \left(\theta s-\alpha-\frac{2 \pi}{3}\right) \\
& \left.+i s c_{1} \cdot \cos \left(\theta s-\frac{4 \pi}{3}\right)+i s c_{2} \cdot \cos \left(\theta s-\alpha-\frac{4 \pi}{3}\right)\right]
\end{aligned}
$$

By expanding each cosine term, the expression Eq. 23 can be put in the following form:

$$
M M F(\theta s)=K\{i d \cos \theta s+i q \sin \theta s\}
$$

So we can say that the MMF produced by the two stars is the same as the MMF produced by two orthogonal windings, named $d$ and $q$. The currents flowing in these windings are $i d$ and $i q$, and are defined with the transformation described in Eq. 25 knowing that:

$$
\left[\begin{array}{c}
i d \\
i q
\end{array}\right]=\left[\begin{array}{c}
\mathbf{d}^{T} \\
\mathbf{q}^{T}
\end{array}\right] \mathbf{I s}
$$

This simple approach allows to obtain the first part of the transformation, that is to say vectors $d$ and $q$, which are related to the rotating MMF and then to electromechanical energy conversion. But it is not enough. In fact, if we consider the stator system, it is a six-dimensional system and mathematically, it cannot be reduced to a two-dimensional system. So, four other vectors must be found to form the new orthogonal base. Two among these four vectors are the well-known zero-sequence vectors associated to each star (Eq. 26). The vectors are named $o 1$ and $o 2$, they must be orthogonal each to the other, and orthogonal to vectors $d$ and $q$.

$$
\mathbf{o}_{1} \mathbf{d}^{T}=\mathbf{o}_{1} \mathbf{q}^{T}=\mathbf{o}_{2} \mathbf{d}^{T}=\mathbf{o}_{2} \mathbf{q}^{T}=0
$$

The remaining two vectors, named $x$ and $y$, must satisfy the same conditions: they must be orthogonal each to the other, and orthogonal to vectors $d, q, o_{1}$ and $o_{2}$.

The solution proposed here is to find vectors having the following form Eq. 29 using two arbitrary angles $A$ and $B$.

Hence, vectors $x$ and $y$ are already orthogonal to vectors $o_{1}$ and $o_{2}$. So, the remaining constraints are:

$$
\mathbf{x d}^{T}=\mathbf{x q} \mathbf{q}^{T}=\mathbf{y d}^{T}=\mathbf{y q}^{T}=0 \ldots \ldots \ldots \ldots \ldots \ldots
$$

Using Eq. 29 and Eq. 33 implies:

$$
\left\{\begin{array}{l}
\mathbf{x d} \mathbf{d}^{T}=3 \cos \left(\frac{A+B}{2}\right) \cdot \cos \left(\frac{A-B}{2}\right)=0 \\
\mathbf{y q}^{T}=-3 \cos \left(\frac{A+B}{2}\right) \cdot \cos \left(\frac{A-B}{2}\right)=0 \\
\mathbf{y d}=3 \sin \left(\frac{A+B}{2}\right) \cdot \cos \left(\frac{A-B}{2}\right)=0 \\
\mathbf{x q}^{T}=\quad 3 \sin \left(\frac{A-B}{2}\right) \cdot \cos \left(\frac{A+B}{2}\right)=0
\end{array}\right.
$$

which results in:

$$
\begin{cases}\frac{(A+B)}{2} & =k_{1} \frac{\pi}{2} \\ \frac{(A-B)}{2} & =k_{2} \frac{\pi}{2}\end{cases}
$$

with $k_{1}=1,3, \ldots, k_{2}=1,3, \ldots$.

Consequently, it yields to:

$$
\left\{\begin{array}{l}
A=(k 1+k 2) \pi / 2 \\
B=(k 1-k 2) \pi / 2
\end{array}\right.
$$

Putting $k 1=1$ and $k 2=1$ results in the following sub-matrix 29 and we have the relation:

$$
\left[\begin{array}{c}
i x \\
i y
\end{array}\right]=\left[\begin{array}{c}
\mathbf{x}^{T} \\
\mathbf{y}^{T}
\end{array}\right] \mathbf{I s}
$$

Since vectors $x$ and $y$ are orthogonal to vectors $d$ and $q$, it can already be expected that the $(x-y)$ variables will not be related to electromechanical energy conversion.

The final normalized transformation $\mathbf{T s}(\alpha)^{-1}$ is given by Eq. 31 .

$\left[\begin{array}{c}i d \\ i q\end{array}\right]=\left[\begin{array}{cccccc}\cos 0 & \cos \frac{2 \pi}{3} & \cos \frac{4 \pi}{3} & \cos \alpha & \cos \left(\alpha+\frac{2 \pi}{3}\right) & \cos \left(\alpha+\frac{4 \pi}{3}\right) \\ \sin 0 & \sin \frac{2 \pi}{3} & \sin \frac{4 \pi}{3} & \sin \alpha & \sin \left(\alpha+\frac{2 \pi}{3}\right) & \sin \left(\alpha+\frac{4 \pi}{3}\right)\end{array}\right] \cdot\left[\begin{array}{llllll}\text { isa } a_{1} & \text { isb } b_{1} & \text { isc } c_{1} & \text { isa } & \text { isb } & \text { isc }\end{array}\right]^{T}$

$\left[\begin{array}{l}i o_{1} \\ i o_{2}\end{array}\right]=\left[\begin{array}{llllll}1 & 1 & 1 & 0 & 0 & 0 \\ 0 & 0 & 0 & 1 & 1 & 1\end{array}\right] \cdot\left[\begin{array}{llllll}i s a_{1} & i s b_{1} & i s c_{1} & i s a_{2} & i s b_{2} & i s c_{2}\end{array}\right]^{T}=\left[\begin{array}{c}\mathbf{o}_{1}{ }^{T} \\ \mathbf{o}_{2}{ }^{T}\end{array}\right] . \mathbf{I s}$ 


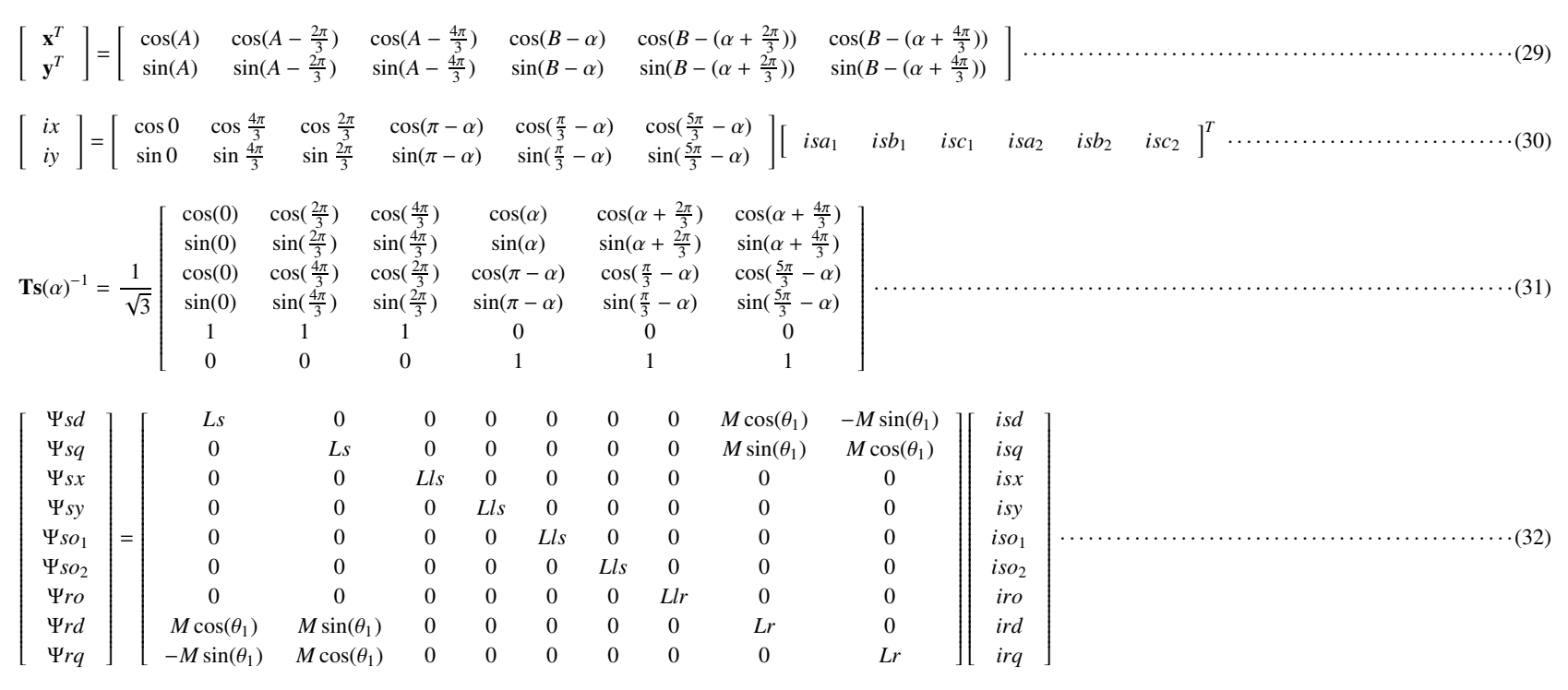

4.2 Model in $(d-q)(x-y)(o 1-o 2)$ Frames In order to develop a suitable dynamic model, the transformation matrix $\mathbf{T s}(\alpha)^{-1}$, which has $\alpha$ as a parameter, is used to obtain a diagonal stator inductance matrix. Applying $\mathbf{T s}(\alpha)^{-1}$ to the voltage and flux equations, the original six-dimensional stator system can be decomposed into three two-dimensional decoupled subsystems. These are the usual $(d-q)$ one, a zero sequence $(o 1-o 2)$ one, and one subsystem called $(x-y)$ corresponding to the non-electromechanical energy conversion as showed in Fig. 4. The transformation has the property to separate harmonics into different groups and to project them into each subsystem. These harmonic groups are those we have underscored thanks to the complex steady state model.

For the rotor variables, the usual transformation of Concordia is used:

$$
\mathbf{T r}^{-1}=\sqrt{\frac{2}{3}}\left[\begin{array}{ccc}
\frac{1}{\sqrt{2}} & \frac{1}{\sqrt{2}} & \frac{1}{\sqrt{2}} \\
\cos (0) & \cos \left(\frac{2 \pi}{3}\right) & \cos \left(\frac{4 \pi}{3}\right) \\
\sin (0) & \sin \left(\frac{2 \pi}{3}\right) & \sin \left(\frac{4 \pi}{3}\right)
\end{array}\right] \cdots \cdots
$$

Vectors of transformed variables (with a subscript $t$ ) are:

$$
\begin{array}{r}
\mathbf{G s} t=\left[{ }_{\text {gsd }} \text { gsq gsx gsy gso } 1 \text { gso } 2\right]=\mathbf{T} \mathbf{s}(\alpha)^{-1} \mathbf{G s} \\
\ldots \ldots \ldots \ldots \ldots \ldots \ldots \\
\mathbf{G r} t=[\text { gro grd } g r q]=\mathbf{T r}^{-1} \mathbf{G r} \ldots \ldots \ldots \ldots \ldots \ldots
\end{array}
$$

Applying these transformations to Eq. 9 yields:

$$
\begin{aligned}
& {\left[\begin{array}{c}
\boldsymbol{\Psi} \mathbf{s} t \\
\boldsymbol{\Psi} \mathbf{r} t
\end{array}\right]=\left[\begin{array}{cc}
\mathbf{T} \mathbf{s}(\alpha)^{-1} & \mathbf{0}_{6 \times 3} \\
\mathbf{0}_{3 \times 6} & \mathbf{T r}^{-1}
\end{array}\right]} \\
& {\left[\begin{array}{ll}
\mathbf{L s s} & \mathbf{M s r} \\
\mathbf{M s r}^{T} & \mathbf{L r}
\end{array}\right]\left[\begin{array}{ll}
\mathbf{T s}(\alpha) & \mathbf{0}_{6 \times 3} \\
\mathbf{0}_{3 \times 6} & \mathbf{T r}
\end{array}\right]\left[\begin{array}{c}
\mathbf{I s}(t) \\
\mathbf{I r}(t)
\end{array}\right]}
\end{aligned}
$$

knowing that:

$$
\left\{\begin{array}{l}
L s=L l s+3 L m s \\
M=\frac{3}{\sqrt{2}} M s r \\
L r=L l r+\frac{3}{2} L m r
\end{array}\right.
$$

The result is given by Eq. 32 .

The next step is to transform the rotor variables into the stator reference frame using the following rotation transformation:

$$
\mathbf{P}\left(-\theta_{1}\right)=\left[\begin{array}{rrr}
1 & 0 & 0 \\
0 & \cos \left(-\theta_{1}\right) & -\sin \left(-\theta_{1}\right) \\
0 & \sin \left(-\theta_{1}\right) & \cos \left(-\theta_{1}\right)
\end{array}\right] \ldots \ldots \ldots
$$

So, rotor variables expressed in the stator reference frame become:

$$
\left[\operatorname{grog}_{r d}^{s} g_{r q}^{s}\right]^{T}=\mathbf{P}\left(-\theta_{1}\right)^{T}[\text { gro grd grq }]
$$

Finally, applying the same transformations to Eq. 1, and eliminating the zero-sequence components $(o 1-o 2)$ and ro which are supposed to be non-existent, results in Eq. 43.

The machine model is then greatly simplified. Hence, the electromagnetic torque expression is given as:

$$
T=p M\left(i_{s q}^{s} i_{r d}^{s}-i_{s d}^{s} i_{r q}^{s}\right)
$$

where $p$ is the number of pole pairs.

In the case of non-sinusoidal balanced supply, the variables of each subsystem are composed of the harmonic groups underscored with the complex steady state model: the $(d-q)$ variables correspond to the type $C$ harmonics and the $(x-y)$ variables to the type $\mathrm{NC}$ harmonics. In fact it can be noticed from Eq. 40 that only $(d-q)$ variables depend on the magnetizing inductance $M$. So only $(d-q)$ stator variables can interact with the rotor and then produce rotating MMF. Equation 46 shows that the torque does not depend on $(x-y)$ components.

Since these $(x-y)$ variables do not produce any rotating MMF, their equivalent circuit cannot include rotor parameter. In particular, it consists only in stator resistance and leakage inductance. In multi-phase AC machines, this leakage inductance is generally small. So, when these machines are supplied by voltage source converters, large stator $(x-y)$ harmonic currents can appear and produce extra losses which can damage the power electronic devices. Consequently, larger semiconductor device ratings are required. Clearly, this drawback contradicts the concept of power segmentation, which normally allows the use of lower rating power electronic devices at higher switching frequency. Therefore, these harmonics should be filtered with a cancelling reactor $^{(15)}$, or controlled to be as small as possible. 


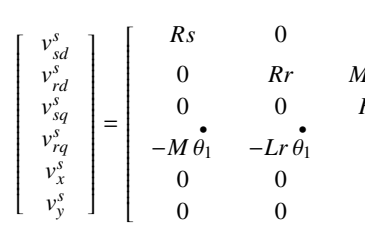

As seen in the previous section, for some particular values of a, balanced voltages are free from these harmonics. For the other values, one solution is to synthesize the voltages by PWM, in such a way that they contain minimum amplitude $(x-y)$ harmonics. This can be achieved by an appropriate space vector PWM control strategy ${ }^{(16)-(18)}$.

It must be noticed that in the study presented in this paper, the leakage inductance $L l s$ has been supposed to be constant and not depending on the shift angle between the two stars. It is shown ${ }^{(19)(20)}$ that in three-phase windings, this leakage inductance depends on the coil pitch because of the mutual leakage coupling existing between the different phases. With the same approach, it can be expected that in dual three-phase windings, this leakage inductance depends also on the shift angle. A more detailed analysis, which takes into account the mutual leakage coupling between both stars, was studied on a $15 \mathrm{~kW}$ machine ${ }^{(24)}$. Several winding configurations with different coil pitches and different shift angles are also investigated to find the arrangement that minimises the mutual leakage coupling. The effect of the shift angle on the total leakage inductance associated to $(x-y)$ variables will be reported in the near future.

\section{Sine-triangle PWM control}

The drive system is a double three-leg VSI fed DSIM as shown in Fig. 6. A sine-triangle PWM operation has been
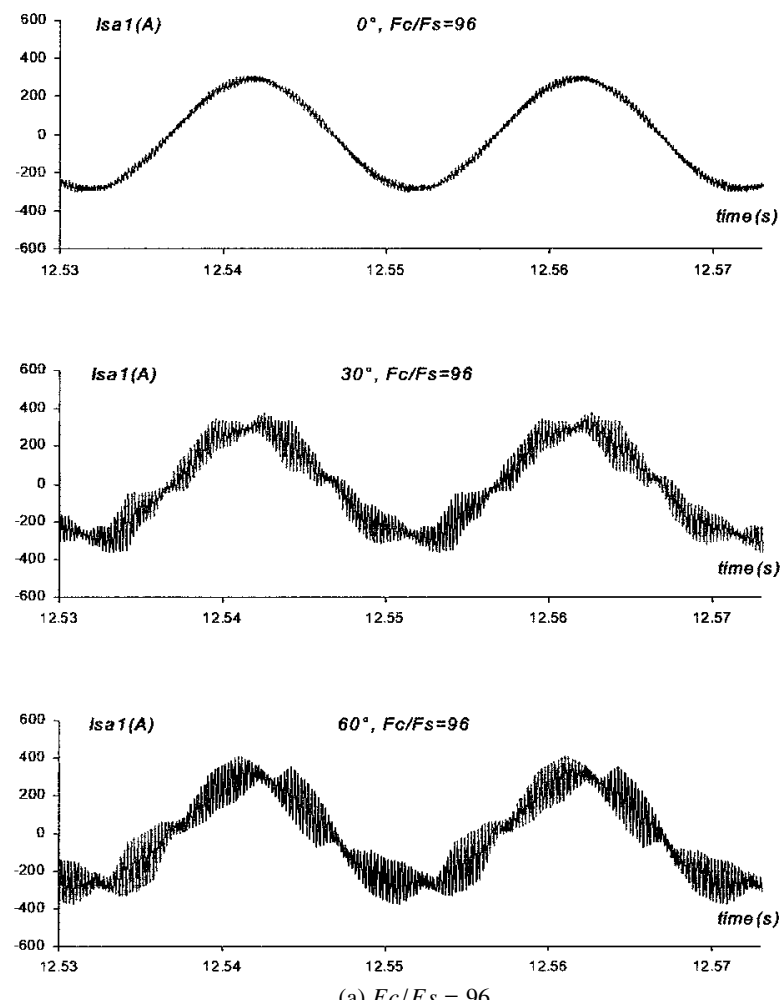

simulated for different shift angles and different switching frequencies $F c$, with the parameters of a $1.3 \mathrm{MW}$ machine ${ }^{(21)}$ ( 8 poles, $1600 \mathrm{~V}, 50 \mathrm{~Hz}$ ). The frequency of the stator voltages is $F s=50 \mathrm{~Hz}$. Simulation results are presented in figures 7 , 8, and 9. A lot of parameters and values can be found in Table 1 located in the appendix.

These results show that the ratio $h c=F c / F s$, which represents the switching harmonic, has a very significant effect on the current waveforms.

For the case $\alpha=60^{\circ}$, the difference between $h c=96$ and $h c=99$ is important: large over currents can be observed in

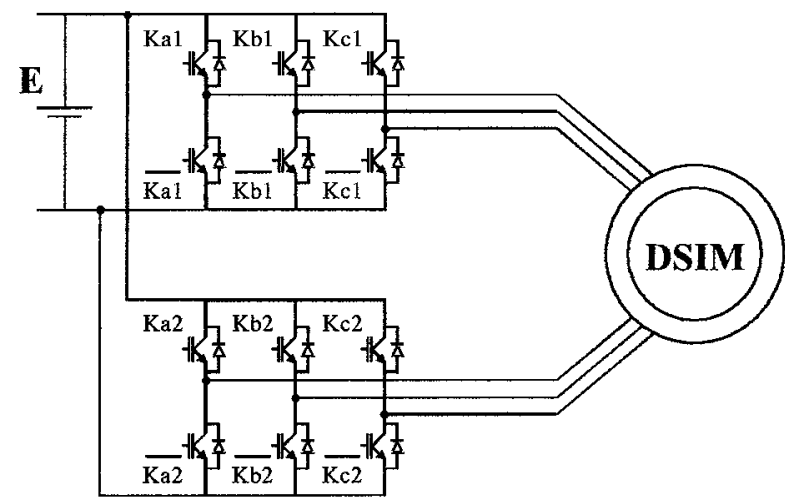

Fig. 6. Drive system
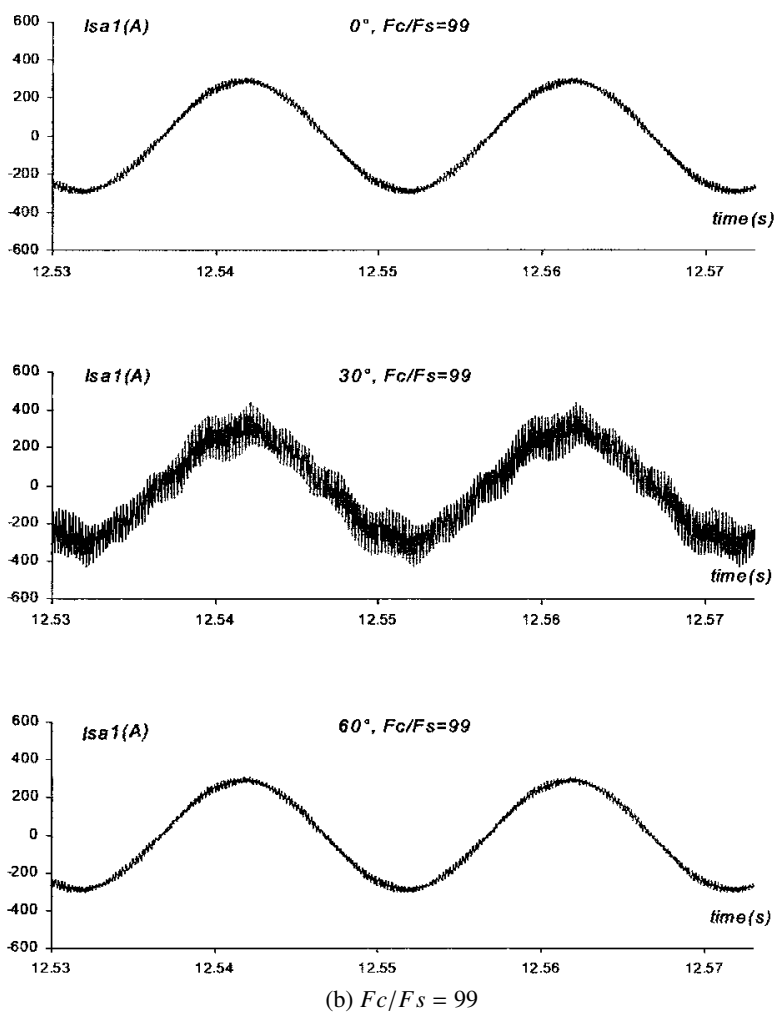

(b) $F c / F s=99$

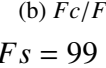




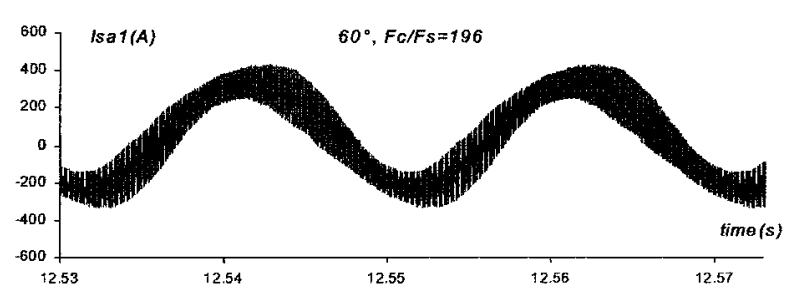

Fig. 8. Stator current in phase $s a_{1}: F c / F s=196$ and $\alpha=60^{\circ}$

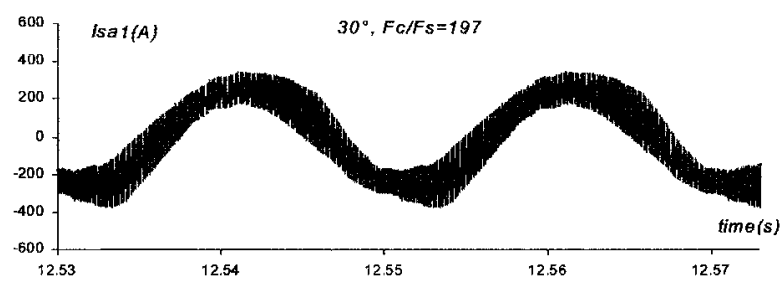

Fig. 9. Stator current in phase $s a_{1}: F c / F s=197$ and $\alpha=30^{\circ}$

the first case because $h c=96$ cannot guarantee that the voltages generated with the sine-triangle intersection have exact symmetrical waveforms. In this case, even harmonics are, then, different from nil, and generate over-currents.

Moreover, $h c=99$ gives much better current waveforms than $h c=196$, even if the switching frequency is twice lower. The same observation is made with $\alpha=30^{\circ}$, between $h c$ $=96$ and $h c=197$. These surprising observations are simply explained by the fact that for each case, the inappropriate switching harmonic belongs to each $(x-y)$ harmonic group.

As expected, the case $\alpha=0^{\circ}$ shows the best current waveforms because for this configuration, balanced voltages are always free from $(x-y)$ components. So $(x-y)$ harmonic currents can appear only in unbalanced operations ${ }^{(2)}$. All these observations confirm the correctness of the previous studies.

As a consequence, for a speed control for example, $F c$ does not need to be constant because in this case the switching harmonic and the voltage harmonic spectrum will change if the speed reference changes. The switching harmonic is the important parameter that must be kept constant to always guarantee the same adequate harmonic spectrum. So, synchronous $\mathrm{PWM}^{(23)}$ is required for $\alpha=60^{\circ}$ and $\alpha=30^{\circ}$.

However, for $\alpha=60^{\circ}$, it is possible to completely eliminate $(x-y)$ harmonics with any $\mathrm{Fc}$ by using an appropriate space vector PWM strategy ${ }^{(18)}$. With the space vector approach, the inverter switches are not considered separately, but as a whole, and they are always synchronized.

For a final choice of one or another winding configuration, several criteria must be taken into account:

- the effect of $\alpha$ on $(x-y)$ harmonic currents;

- the effect of $\alpha$ on the space harmonics of the air-gap MMF;

- the effect of $\alpha$ on the leakage inductance.

\section{Space vector PWM control}

The drive system is again the double three-leg VSI fed DSIM as shown in Fig. 6. A combinatorial analysis of the inverter switch state shows 64 switching modes. So, 64 different voltage vectors can be applied to the machine. By using the proposed transformation, we can decompose them into the $(d-q)(x-y)(o 1-o 2)$ voltages. The $(o 1-o 2)$ ones are all equal to zero because the two three-phase windings are wye-connected with isolated neutrals. So, the aim of the PWM is to generate maximum $(d-q)$ voltages and minimum $(x-y)$ voltages. The choice of particular switching modes allows to satisfy both conditions.

By choosing the switching modes which permit to have the maximum amplitude $(d-q)$ voltage vectors, we obtain the planes shown in Fig. 10 and Fig. 11, where each switching mode is represented by a decimal number corresponding to the binary number $(K c 2 K b 2 K a 2 K c 1 K b 1 K a 1)_{2}$. This number gives the state of the upper switches.

We can notice that for $\alpha=60^{\circ}$ and $\alpha=0^{\circ}$, the chosen switching modes do not generate $(x-y)$ voltage vectors. For $\alpha=30^{\circ},(x-y)$ voltage vectors are not equal to zero but they have smaller amplitude than the $(d-q)$ voltage vectors. So, it can be expected that the calculation of the space vector PWM control strategy will be more difficult to make for $\alpha=30^{\circ}$ than for $\alpha=60^{\circ}$ and $\alpha=0^{\circ}$, and it will require more consuming time. In fact, for these last cases, the choice of only two voltage vectors on $(d-q)$ plane is sufficient since no control is needed on $(x-y)$ plane. On the contrary, because of the existence of $(x-y)$ voltage vectors for $\alpha=30^{\circ}$, it is necessary to choose four voltage vectors on $(d-q)$ plane in order to make possible the control on $(x-y)$ plane at the same time.

Each PWM is calculated thanks to the following equation: Calculation of PWM for the angle $\alpha=0^{\circ}$ and $\alpha=60^{\circ}$ :

$$
T_{1} \overrightarrow{V_{d q_{1}}}+T_{2} \overrightarrow{V_{d q_{2}}}=T_{e} \overrightarrow{V_{d q_{i}}} \text { ref }
$$

with the constraint: $T_{1}+T_{2}+T_{n}=T_{e}$.

Calculation of $P W M$ for the angle $\alpha=30^{\circ}$ :

$$
\begin{aligned}
& T_{1}{\overrightarrow{V_{d q_{1}}}}+T_{2}{\overrightarrow{V_{d q_{2}}}}+T_{3} \overrightarrow{V_{d q_{3}}}+T_{4} \overrightarrow{V_{d q_{4}}}=T_{e} \overrightarrow{V_{d q_{i}}} \text { ref } \\
& T_{1} \overrightarrow{V_{x y_{1}}}+T_{2} \overrightarrow{V_{x y_{2}}}+T_{3} \overrightarrow{V_{x y_{3}}}+T_{4} \overrightarrow{V_{x y_{4}}}=\overrightarrow{0}
\end{aligned}
$$

with the constraint: $T_{1}+T_{2}+T_{3}+T_{4}+T_{n}=T_{e}$.

The $\overrightarrow{V_{d q_{i}}}$ is the complex voltage vector generated by the switching mode $i$, and $T_{i}$ the application time of that vector. $T_{n}$ is the application time of the zero voltage vector and $T_{e}$ the sampling period of the reference voltage vector ${\overrightarrow{V_{d q}}}_{i}$ ref.

In three-leg VSI, the zero voltage vector can be generated by two switching modes:

- mode 0: all the upper switch state at 0;

- mode 7: all the upper switch state at 1 . In order to obtain the minimum number of commutations during the sampling period $T e$, mode 7 is usually placed in the middle of $T e$ and mode 0 in its beginning and end ${ }^{(23)}$.

In double three-leg VSI, the zero voltage vector on $(d-q)$ plane can be generated by four switching modes:

- mode 0: all the upper switch state at 0;

- mode 63: all the upper switch state at 1;

- mode 7: upper switches of star $n^{\circ} 1$ at 1 and upper switches of star $n^{\circ} 2$ at 0 ;

- mode 56: upper switches of star $n^{\circ} 1$ at 0 , and upper switches of star $n^{\circ} 2$ at 1 .

Whatever the value of the shift angle $\alpha$, these four switching modes are the same. The arrangement of this vector and of 


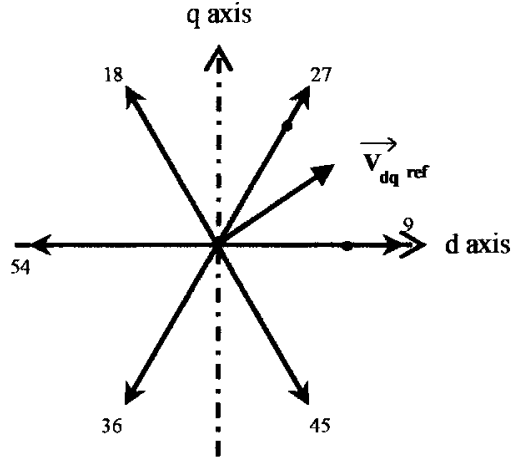

(a) vectors on $(d-q)$

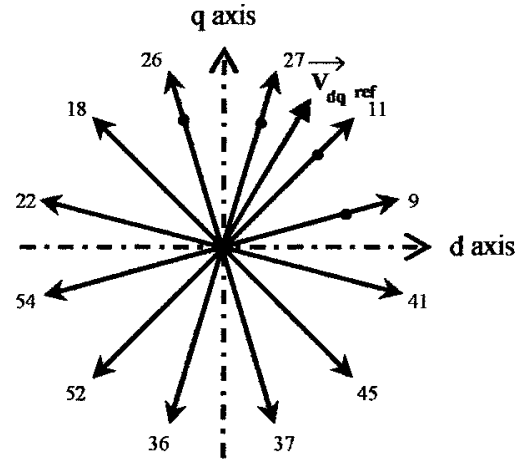

(b) vectors on $(d-q)$

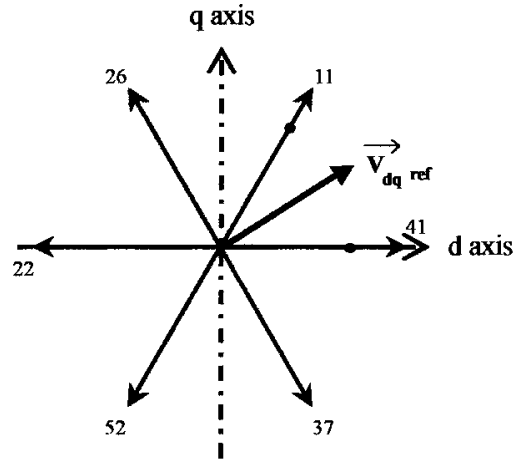

(c) vectors on $(d-q)$

Fig. 10. Inverter voltage vectors corresponding to the chosen switching modes for: (a) $\alpha=0^{\circ}$, (b) $\alpha=30^{\circ}$, (c) $\alpha=60^{\circ}$

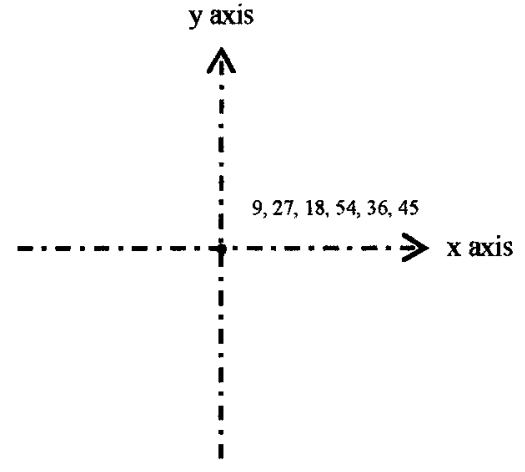

(a) vectors on $(x-y)$

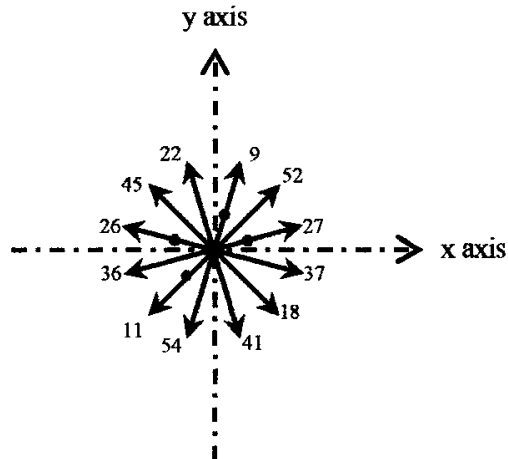

(b) vectors on $(x-y)$

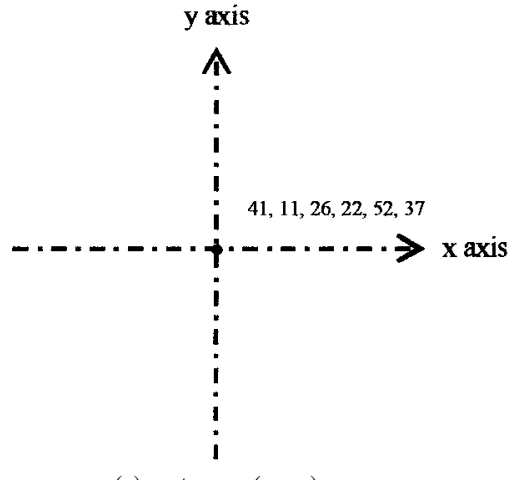

(c) vectors on $(x-y)$

Fig. 11. Inverter voltage vectors corresponding to the chosen switching modes for: (a) $\alpha=0^{\circ}$, (b) $\alpha=30^{\circ}$, (c) $\alpha=60^{\circ}$

the others during the sampling period is important and an appropriate use of mode 7 and mode 56 rather than mode 0 and mode 63 can minimise the number of commutations. As an example, for $\alpha=60^{\circ}$, the use of mode 56 rather than mode 0 and mode 7 rather than mode 63 guarantees a minimum number of commutations, and a constant switching frequency that is equal to $(T e / 2)$.

The space vector PWM for the DSIM implies the necessity to choose four voltage vectors plus one zero voltage vector on $(d-q)$ plane (Fig. 10(b)) in order to make possible the control on $(x-y)$ plane (Fig. 11(b)) at the same time.

Since we must apply five vectors during the sampling period $T_{e}$, there is a lot of choices for the arrangement of these vectors. Nevertheless, lots of them do not minimise the undesirable harmonics, and the solution is not so immediate.

6.1 Arrangement of the vectors during $\boldsymbol{T}_{\boldsymbol{e}} \quad$ The method proposed in this paper is to choose the arrangement in such a way that on the $(x-y)$ plane, two consecutive vectors are practically opposite to each other in phase. For example, in the case shown in Fig. 10(b) where the $(d-q)$ voltage vector reference is located in the sector delimited by $\vec{V}_{d q_{11}}$ and ${\overrightarrow{V_{d q}}}_{27}$, the switching modes $11,27,9$ and 26 are chosen. The arrangement $9-11-27-26$ or 26-27-11-9 guarantees that two consecutive $(x-y)$ voltage vectors have opposite directions (Fig. 11(b)).

By this way, each change of applied vectors will lead to a succession of increase and decrease in $(x-y)$ currents around zero. Moreover, since the projection of the chosen voltage

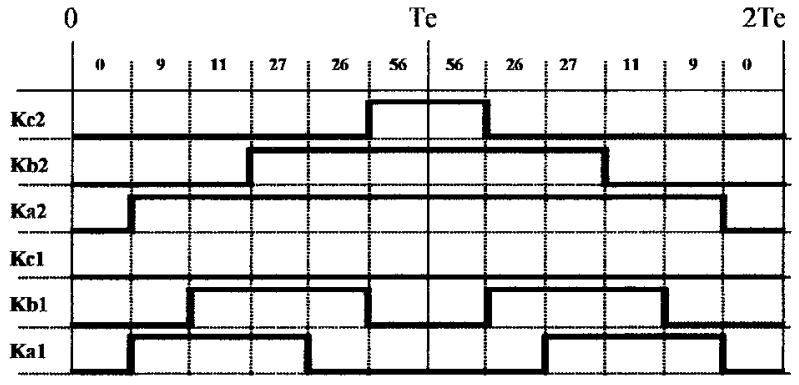

Fig. 12. Inverter switches state

vectors in $(x-y)$ plane is minimum, the proposed method will minimise the $(x-y)$ current peak values.

6.2 Switching Frequency For a double three-leg VSI, the zero voltage vector can be generated by four switching modes. So, once the arrangement fixed, the switching frequency is determined by the choice and position of this vector.

One solution minimizing the instantaneous switching frequency is presented in Fig. 12. The first immediate observation is the dissimilar instantaneous switching frequency between the switches. Inside the sector presented here, this one equals $(1 / 2 T e)$ for $K c 2-K b 2-K a 2,(1 / T e)$ for $K b 1-K a 1$, and 0 for $K c 1$. Of course, during a cycle of the reference voltage, each switch has the same global switching distribution. The average switching frequency, even if it is not a significant criteria in high power applications, is around $(1 / 2 T e)$. 

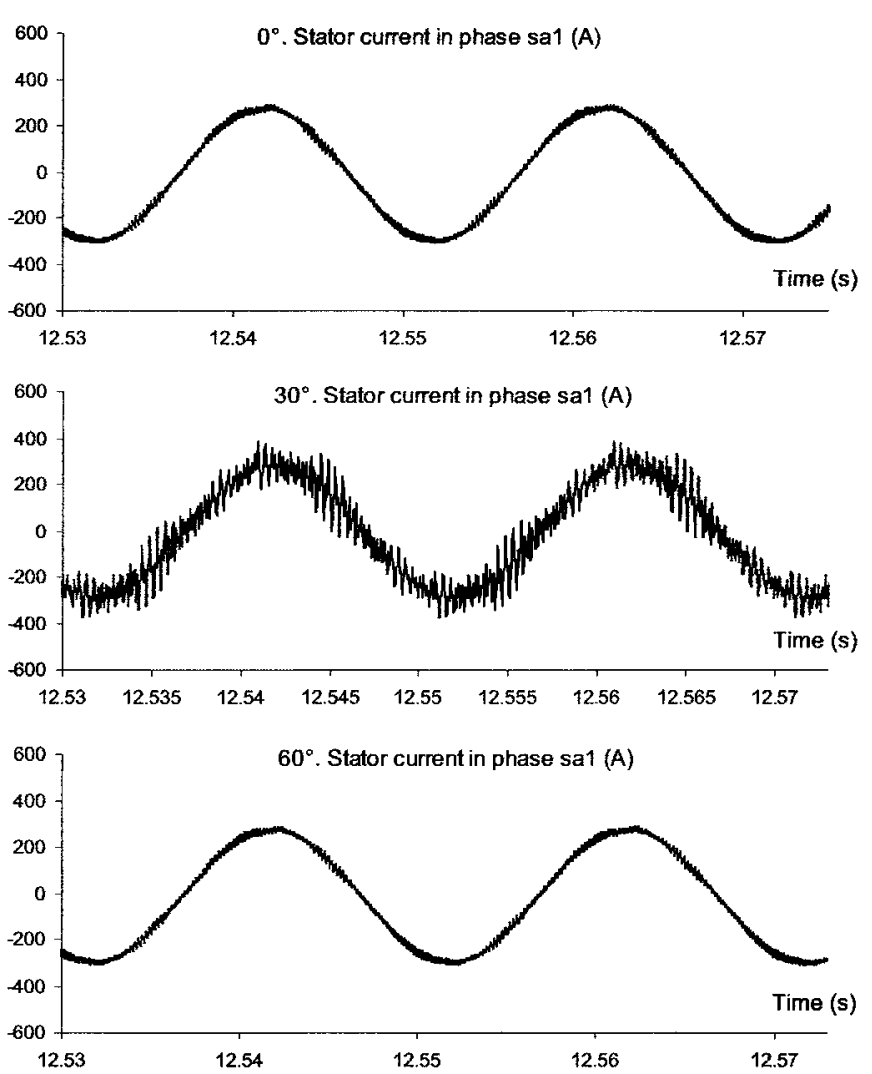

Fig. 13. Simulation results of the space vector PWM control of the DSIM $(F c / F s=96)$. Stator current in phase $s a_{1}: \alpha=0^{\circ}, \alpha=30^{\circ}$ and $\alpha=60^{\circ}$

Compared to other carrier based PWM such as sine-triangle PWM, it is practically the half.

6.3 Simulation Results For each value of the shift angle $\alpha$, the space vector PWM control of the DSIM has been simulated. As expected, the cases $\alpha=60^{\circ}$ and $\alpha=30^{\circ}$, present the best current waveforms since $(x-y)$ harmonic currents do not exist. For $\alpha=30^{\circ}$, the existence of $(x-y)$ harmonic components produce large current ripples. Nevertheless, the space vector PWM control strategy maintains the average volt-second $(x-y)$ currents at zero and then, it minimises their undesirable effects, compared to other types of $\mathrm{PWM}^{(9)}$.

From the previous study, it can be concluded that for the PWM control of the double three-leg VSI fed DSIM, the choice of shifting the two three-phase windings by a usual electrical angle of $\alpha=30^{\circ}$, is not the best.

A shift angle of $\alpha=60^{\circ}$ or $\alpha=0^{\circ}$ simplifies a lot the space vector PWM control a lot and the consequence on the stator current waveforms is very significant: over currents due to the $(x-y)$ harmonics are reduced to zero.

\section{Comparison Between Sine-triangle PWM and Space Vector PWM Control}

For purpose of comparison, the sine-triangle PWM has also been simulated using the same sampling period $T e$. The results are presented in the following figures.

Compared to the sine-triangle PWM, it appears that using the space vector PWM control, the $(x-y)$ harmonics have been minimized and the impact on the stator phase current is

Table 2. Some simulation results

\begin{tabular}{|l|r|r|}
\hline & sine-triangle & space vector \\
\hline$I s a_{1}$ rms (A) & $242.7 \mathrm{~A}$ & $239.6 \mathrm{~A}$ \\
\hline THD & $17.89 \%$ & $7.47 \%$ \\
\hline$I x \mathrm{rms}(\mathrm{A})$ & $132.9 \mathrm{~A}$ & $29.4 \mathrm{~A}$ \\
\hline
\end{tabular}

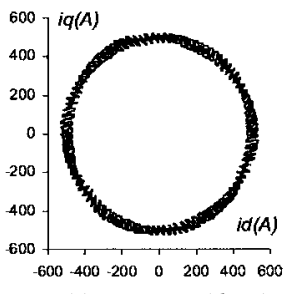

(a) vectors on $(d-q)$

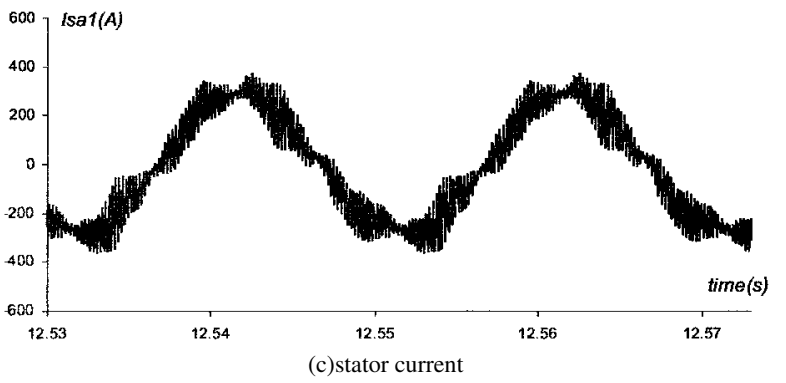

Fig. 14. Sine-Triangle PWM $(F c / F s=99)$ : (a) $(d-q)$ plane current trajectory, (b) $(x-y)$ plane current trajectory, (c) stator current in phase $s a_{1}$
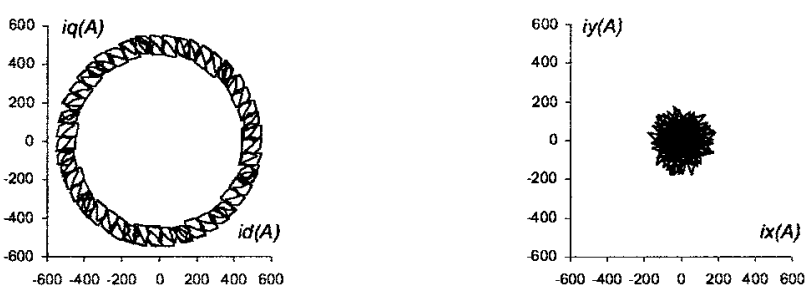

(a) vectors on $(d-q)$ (b) vectors on $(x-y)$

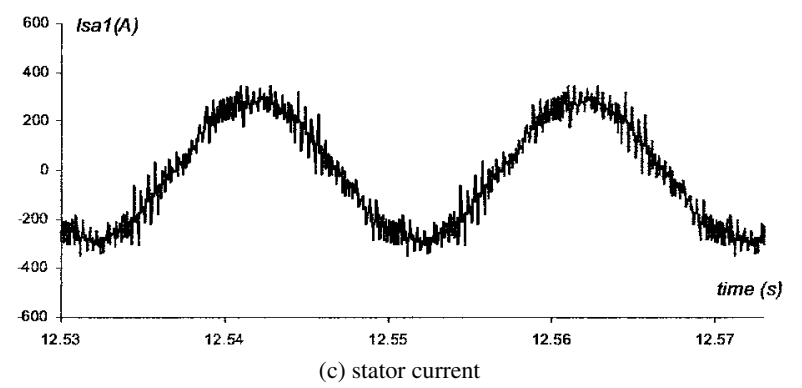

Fig. 15. Space vector PWM $(F c / F s=99)$ : (a) $(d-q)$ plane current trajectory, (b) $(x-y)$ plane current trajectory, (c) stator current in phase $s a_{1}$

significant. Since the PWM strategy has to control the two planes at the same time, an improvement on one plane affects inevitably the other plane.

Table 2 presents some relevant results like the $r m s$ value of the stator current of one phase, the THD corresponding to the sine-triangle PWM and to the space vector PWM. As we can see, the THD is lower in case of space vector modulation $(7.47 \%$ instead of $17.89 \%)$ and the value of the current in the $(x-y)$ frame is awfully lower in case of space vector PWM (29.4 A instead of 132.9 A). Consequently, the extra losses causes by harmonics will be considerably reduced.

In fact, it is observed that there is a little loss of control on 
$(d-q)$ plane, which can imply some little ripple on the electromagnetic torque. However, this comparison is not so good because, as mentioned in the previous section, the switching frequency of an individual switch is not constant, and the average switching frequency is practically the half of the one of the sine-triangle PWM $(1 / T e)$.

\section{Conclusion}

The analysis and the modelling of a Dual-Stator Induction Motor have been presented. A complex steady state model has been developed and a new transformation matrix has been proposed to obtain a dynamic model. In both cases, the study is made using an arbitrary shift angle between the two threephase windings. The effects of the shift angle on the dynamic performance have been pointed out. Moreover, the switching frequency is an important parameter that must be chosen correctly. In fact, when the Dual-Stator Induction Motor is supplied by a Voltage Source Inverter, synchronous PWM should rather be employed to limit the impact of circulating harmonic currents. Simulation results have also been presented, and they confirm the correctness of the theoretical analysis. The methods proposed in this paper are not restrictive and they can be extended to the study and the analysis of other kinds of AC machines, with any number of stator phases. AC machines with more than two stator three-phase windings for example, or with high odd number of stator phases can be studied in the same way.

(Manuscript received Nov. 24, 2004, revised June 13, 2005)

\section{References}

( 1 ) T.M. Jahns: "Improved Reliability in Solid State AC Drives by Means of Multiple Independent Phase-Drive Units", IEEE Trans. Ind. Appl., Vol.IA16, No.3, pp.321-331, May/June (1980)

( 2 ) D. Roger, J.F. Brudny, and F. Notelet: "Electrical Drives using Double-Star Induction Machine”, SPEEDAM 1992, Positano, Italy, pp.11-16, 19-21 May (1992)

( 3 ) K.H. Kettler: "Multisystem Propulsion Concept on the Basis of the DoubleStar Circuit", EPE'1995, Vol.2, pp.159-166 (1995)

( 4 ) Z. Chen and A.C. Williamson: "Simulation Study of a Double Three Phase Electric Machine”, ICEM'1998, 2-4 September 1998, Istanbul, Turkey, Vol. 1, pp.215-220 (1998)

( 5 ) M.A. Abbas, R. Christen, and T.M. Jahns: "Six-Phase Voltage Source Inverter Driven Induction Motor", IEEE Trans. Ind. Appl., Vol.IA-20, No.5, pp.1251-1259, Sept./Oct (1984)

( 6 ) K. Gopakumar, V.T. Ranganathan, and S.R. Bhat: "Split Phase Induction Motor Operation from PWM Voltage Source Inverter", IEEE Trans. Ind. Appl., Vol.29, No.5, pp.927-932, Sept./Oct. (1993)

( 7 ) E.A. Klingshirn: "High Phase Order Induction Motors-Part I-Description and Theoretical Considerations", IEEE Trans. Power App. Syst., Vol.PAS-102, No.1, pp.47-53, Jan. (1983)

( 8 ) E.A. Klingshirn: "High Phase Order Induction Motors-Part II-Experimental Results", IEEE Trans. Power App. Syst., Vol.PAS-102, No.1, pp.54-59, Jan. (1983)

( 9 ) R.H. Nelson and P.C. Krause: "Induction Machine Analysis for Arbitrary Displacement Between Multiple Winding Sets", IEEE Trans. Power App. Syst., Vol.PAS-93, pp.841-848, May/June (1974)

(10) D. Hadiouche, H. Razik, and A. Rezzoug: "Modelling of A Double-Star Induction Motor With An Arbitrary Shift Angle Between Its Three Phase Windings”, EPE-PEMC'2000, Kosice, Slovak Republic, Vol.5, pp.125-130, 5-7 September (2000)

(11) E. Andersen and K. Bieniek: "6-Phase Induction Motors for Current Source Inverter Drives", 16th Annual Meet. IEEE Ind. Appl. Soc., pp.607-618 (1981)

(12) T.A. Lipo and L.H. Walker: "Design and Control Techniques for Extending High Frequency Operation of a CSI Induction Motor Drive", IEEE Trans.
Ind. Appl., Vol.IA-19, No.5, pp.744-753, Sept./Oct. (1983)

(13) K. Gopakumar, S. Sathiakumar, S.K. Biswas, and J. Vithayathil: "Modified Current Source Inverter fed Induction Motor Drive with Reduced Torque Pulsations", IEE Proc., Vol.131, Pt.B, No.4, pp.159-164, July (1984)

(14) K. Taniguchi, M. Inoue, Y. Takeda, and S. Morimoto: "A PWM Strategy for Reducing Torque-Ripple in Inverter-fed Induction Motor", IEEE Trans. Ind. Appl., Vol.30, No.1, pp.71-77, Jan./Feb. (1994)

(15) K. Oguchi, A. Kawaguchi, T. Kubota, and N. Hoshi: "A Novel Six-Phase Inverter System with 60-Step Output Voltages for High-Power Motor Drives", IEEE Trans. Ind. Appl., Vol.35, No.5, pp.1141-1149, Sept./Oct. (1999)

(16) Y. Zhao and T.A. Lipo: "Space Vector PWM Control of Dual Three Phase Induction Machine Using Vector Space Decomposition", IEEE Trans. Ind. Appl., Vol.31, No.5, pp.1100-1109, Sept./Oct. (1995)

(17) D. Hadiouche, H. Razik, and A. Rezzoug: "Modelling of A Double-Star Induction Motor For Space Vector PWM Control”, ICEM 2000, Espoo, Finland, Vol.1, pp.392-396, 28-30 August (2000)

(18) D. Hadiouche, H. Razik, and A. Rezzoug: "Study and Simulation of Space Vector PWM Control of Double-Star Induction Motors", IEEE-CIEP'2000, Acapulco, Mexico, pp.42-47, 15-19 October (2000)

(19) P.L. Alger: Induction Machines, Gordon and Breach Science Publishers, Second Edition (1970)

(20) T.A. Lipo: “A d-q Model for Six Phase Induction Machines", Int. Conf. Electric Machine, pp.860-867, Athens (1980)

(21) A. Monti, A.P. Morando, L. Resta, and M. Riva: " Comparing Two Level GTO-Inverter Feeding a Double Star Asynchronous Motor with a Three Level GTO-Inverter Feeding a Single Star Asynchronous Motor", EPE'1995, Sevilla, Spain, pp.2.419-2.425, 19-21 September (1995)

(22) N. Moubayed, F. Meibody-Tabar, and B. Davat: "Conditions of Safely Supplying of DSIM by two PWM-VSI”, EPE'1999, Lausanne, Switzerland, 7-9 September (1999)

(23) J. Holtz: "Pulsewidth Modulation-A Survey", IEEE Trans. Ind. Electron., pp.410-420, Oct. (1992)

(24) D. Hadiouche, H. Razik, and A. Rezzoug: "On the Modeling and Design of Dual-Stator windings to Minimize Circulating Harmonic Currents for VSI Fed AC Machines", IEEE trans. On Industry Appl., vol.40, No.2, pp.506-515 march/april (2004)

\section{Appendix}

We present in the app. Table 1 a list of some symbols with their corresponding value.

app. Table 1. Liste of symbols and parameters

\begin{tabular}{|ll|l|}
\hline$R_{s} \quad:$ Stator resistance & $0.02507 \Omega$ \\
\hline$L_{l s} \quad:$ Stator leakage inductance & $0.00020 \mathrm{H}$ \\
\hline$L_{m s} \quad:$ Magnetizing inductance & $0.01326 \mathrm{H}$ \\
\hline$M_{s r} \quad:$ Stator-rotor mutual inductances matrix & $0.01284 \mathrm{H}$ \\
\hline$L_{l r} \quad:$ Rotor leakage inductance & $0.00074 \mathrm{H}$ \\
\hline$L_{m r} \quad:$ Magnetizing inductance & $0.01244 \mathrm{H}$ \\
\hline$R_{r} \quad:$ Rotor resistance & $0.01355 \Omega$ \\
\hline
\end{tabular}

Hubert Razik (Non-member) was born in Pompey, France, in

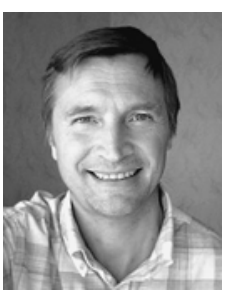
1962. He was graduated from the École Normale Supérieure, Cachan, France, in 1987. He received the Ph.D. degree in Electrical Engineering from the Polytechnic Institute of Lorraine, Nancy, France, in 1991, and received the "Habilitation à Diriger des Recherches" degrees from the University Henri Poincaré, France, 2000. In 1993, he joined the GREEN laboratory, Nancy, France, as an Assistant Professor. He is currently an Associate Professor of Electrical Engineering at the "Institut Universitaire de Formation des Maîtres de Lorraine" and works at the University Henri Poincaré, Nancy, France. He has authored or coauthored more than 70 scientific conferences and journal papers. His fields of research tasks deal with the modelling, the control and the diagnostic of multi-phase induction motor. He is a senior member of the IEEE-IAS 
Abderrezak Rezzoug (Non-member) (1948) is a Professor in Electrical Engineering in the University Henri Poincaré, Nancy, France. As the head of the "Groupe de Recherche en Electrotechnique et Electronique de Nancy" (GREEN), his main subjects of research concern electrical machines, their identification, diagnostic and control, and superconducting applications. He is a member IEEE.

Djafar Hadiouche (Non-member) (1974) received the Ph.D. degree in electrical engineering from the University Henri Poincaré, Nancy, France, in 2001. From 2001 to 2002, he was Assistant Lecturer in the University Henri Poincaré and did research in the GREEN laboratory. His main research interests concern multiphase ac machines, their modeling, identification, PWM techniques, and vector control. Since 2003, he is Motion Specialist Engineer with GE Fanuc Automation Europe, Echternach, Luxembourg. His main tasks include servo-sizing, tools and motion programs development, electronic cam profiling and motion technical training.

These authors received the Best Prize Paper Award from the Electric Machine Committee at the 2001 IEEE Industry Application Society Annual Meeting. 